\title{
Energy Expenditure in the Race Across America (RAAM)
}

Authors

Affiliations

\section{A. T. Hulton ${ }^{1}$, I. Lahart ${ }^{2}$, K. L. Williams ${ }^{1}$, R. Godfrey ${ }^{3}$, S. Charlesworth ${ }^{4}$, M. Wilson ${ }^{5}$, C. Pedlar ${ }^{6}$, G. Whyte}

Affiliation addresses are listed at the end of the article
Key words

doubly labelled water

- energy expenditure

- ultra endurance exercise accepted after revision February 25, 2010

Bibliography DOI http://dx.doi.org/ 10.1055/s-0030-1251992 Published online:

May 7, 2010

Int J Sports Med 2010; 31: 463-467 @ Georg Thieme Verlag KG Stuttgart · New York ISSN 0172-4622

Correspondence

Andrew Thomas Hulton

Liverpool John Moores

University

Research Institute for Sport \&

Exercise Sciences

Tom Reilly Building

L3 3AF Liverpool

United Kingdom

Tel.: + 44/0151/904 6217

Fax:+44/0151/904 6284

a.t.hulton@ljmu.ac.uk

\begin{abstract}
$\nabla$

Energy Expenditure was measured with doubly labelled water technique during heavy sustained exercise with an official finishing team in the Race Across America. Energy Intake was also calculated to produce an energy balance for the race. A team of 4 cyclists (Mean \pm SD age: $37+4 \mathrm{yr}$; body height: $182+8 \mathrm{~cm}$; body mass: $80.8+6.6 \mathrm{~kg}$ ) completed the race in a relay fashion. The team completed the race in 6 days $10 \mathrm{~h}$ and $51 \mathrm{~min}$. Total mean energy expenditure was found to be $43401 \mathrm{kcals}$ ( $181711 \mathrm{~kJ}$ ) with a mean daily energy expenditure of 6420 kcals (26879
\end{abstract}

\section{Introduction}

\section{$\nabla$}

Ultra endurance cycling events such as the Race Across AMerica (RAAM), Tour de France and XXAlps cycle race place huge physiological and psychological demands upon the body. In order to maintain the intensity throughout these races strict dietary strategies need to be employed to maximise the body's glycogen stores and preserve hydration status, thus eliminating the onset of fatigue and any decrements in performance. Investigating energy intake (EI) of successful ultra endurance athletes can provide useful information for future performance. Furthermore, advanced knowledge of the likely energy expenditure (EE) during such events provides the general athletic community, coaches and nutritionists with a better guide and enhances preparation to improve appropriate energy intake.

There are many different techniques for measuring EE, all of which have advantages and limitations. The doubly labelled water (DLW) method is used to validate other methods and is considered the 'gold standard' of EE measurement [1]. This method, for measuring EE in free-living subjects, has been used in human studies for over two dec-
$\mathrm{kJ})$. Total mean energy intake from all food and drink consumed was calculated at 29506 kcals $(123536 \mathrm{~kJ})$ with a mean daily energy intake of 4918 kcals $(20591 \mathrm{~kJ})$. This resulted in a total mean energy deficit of $13878 \mathrm{kcals}$ ( $58104 \mathrm{~kJ}$ ) with a mean daily energy deficit of 1503 kcals $(6293 \mathrm{~kJ})$. The high energy expenditure highlights the need for correct and practical dietary strategies and challenges nutritionists to devise high energy diets that not only contain the correct macronutrient balance, but are also palatable to the cyclists, thus encouraging a high energy intake.

ades. A previous author conducted a validation of the measure and demonstrated that the method was accurate to $1-2 \%$ [18]. More recently the same author concluded that the DLW method has a relative accuracy of $1 \%$, a laboratory-dependent analytical precision of $3 \%$ or greater, and a withinsubject repeatability of 5-8\% [19]. Its precise accuracy and ease of use during testing, which does not cause any interference with the subjects, are advantages that easily outweigh the costs associated with this technique.

There have been many studies that have attempted to investigate the energy expenditure of ultra endurance events using non-stop races and multi stage races. Non-stop races, such as the RAAM (which can be completed as a solo rider or as part of a team) and the XXAlps, require participants to complete the race with no scheduled stops, whereas multi stage event races, such as the Tour de France, are split into several stages with stage finishing times accumulating until the end of the event. A previous study estimated EE for a solo RAAM cyclist to be $17965 \mathrm{kcals}$ using continuous heart rate (HR) monitoring. While a similar study with cyclists competing in the XXAlps [5] found a mean daily EE of $13467 \mathrm{kcal}$ 
measured with continuous HR monitoring compared to a mean daily EE of 9726 kcals measured with the more accurate individual relationship between $\mathrm{HR}$ and $\mathrm{VO}_{2}$. A further two studies have used professional cyclists competing in the Tour de France $[17,25]$ to measure EE, one of which did not use the DLW method and recorded a daily mean EE of 6066 kcals for 4 cyclists [17], while the authors of the second study found that EE increased steadily from $7027 \mathrm{kcal} /$ day at week one to $8532 \mathrm{kcal} /$ day during the third and final week measured with DLW [25].

Although a similar study [25] has explored the EE of ultra endurance cyclists, this study differs as it investigates a non-professional ultra endurance team event during a non-stop race with no professional support. Therefore the aim of this study was to measure energy expenditure, using the gold standard method, for an ultra endurance team event. In addition EI was measured to calculate an energy deficit throughout the race, although EI can be difficult to accurately monitor as errors in reporting are common. These data will provide valuable information for cyclists, coaches and nutritionists for future events.

\section{Method}

$\nabla$

\section{Participants}

Four non-professional, experienced ultra endurance cyclists were recruited for the study (Mean \pm SD: age: $37 \pm 4 \mathrm{yr}$; body height: $182 \pm 8 \mathrm{~cm}$; body mass: $80.8 \pm 6.6 \mathrm{~kg}$ ). Subjects formed the 4 man team and all gave prior written informed consent to participate in the study. The study was performed in accordance with the ethical standards of the International Journal of Sports Medicine [10].

\section{Exercise}

The ultra endurance event used in the current study was the four man team event in the RAAM. This annual event was established in 1982 and is regarded as the toughest cycling race in the world. The RAAM is a continuous cycle event that can be completed by either solo riders or as part of a two, four or eight person team. The 2008 race covered 3014 miles (4851 km), starting on the west coast of America in Oceanside CA, and finishing on the east coast in Annapolis MD. In addition to the long duration, cyclists had to deal with a huge range of climatic changes throughout the event, with temperatures ranging from $-3^{\circ} \mathrm{C}$ to $37^{\circ} \mathrm{C}$ with highly variable humidity. They also faced arduous climbs through the Rockies and Appalachians with a cumulative climb of $110000 \mathrm{ft}$ (33528 metres).

The four cyclists were split into two groups of two cyclists each. Each group followed a $24 \mathrm{~h}$ work-rest approach consisting of two periods of $3 \mathrm{~h}$ cycling and $3 \mathrm{~h}$ recovery, and one period of $6 \mathrm{~h}$ cycling and $6 \mathrm{~h}$ recovery (see $\bullet$ Fig. 1 ). Cyclists would alternate,
15 min on, 15 min off, during their exercise period. These tactics were employed to enable the cyclists to maintain a high power output and the target speed of $20 \mathrm{mph}$ throughout the event. The two cyclists who were not racing would rest, sleep and eat in a mobile home during their resting periods. All support vehicles were equipped with a satellite navigation system and the official road book in order to follow the official route.

\section{Energy intake (EI)}

Weighed food diaries were recorded by the investigators from the start of the race until completion. Details recorded were mass/quantity of all food and drink consumed. Nutrition consisted exclusively of food bought during the race and cooked at the mobile home. Diaries were analysed using the dietary analysis software MicroDiet Plus for Windows Version 11 (MicroDiet, UK). No food restrictions were in force during the RAAM as food and fluids were constantly available to the cyclists in an ad libitum manner, whether they were in the support vehicle on a $15 \mathrm{~min}$ rest period between exercise bouts, or in the mobile home during a 3 or $6 \mathrm{~h}$ rest period. As carbohydrate is the preferred fuel during ultra endurance exercise to maintain glycogen stores [20], the majority of food available was high energy snacks and $\mathrm{CHO}$ electrolyte drinks, with more substantial carbohydrate meals prepared for the cyclists on return to the mobile home and again prior to the cyclists leaving.

\section{Energy expenditure (EE)}

EE was determined by using the DLW method. Baseline urine samples were collected following an overnight fast on the morning of the race. Following collection of baseline samples the isotope dose was administered. Subjects consumed a mixed oral dose of a $10 \%$ enriched $\mathrm{H}_{2}{ }^{18} \mathrm{O}(1.5 \mathrm{~g} / \mathrm{kg}$ body weight $)$ and $99 \%$ enriched ${ }^{2} \mathrm{H}_{2} \mathrm{O}(0.06 \mathrm{~g} / \mathrm{kg}$ body weight). Urine samples were then collected $4 \mathrm{~h}$ post dosing, every $24 \mathrm{~h}$ thereafter and a final sample collected on completion of the race. All samples were collected between $06: 00$ and $12: 00$ and frozen at $-20^{\circ} \mathrm{C}$.

The measurement of ${ }^{2} \mathrm{H}$ (deuterium) was analysed by a Europa Hydra 20/20 continuous flow isotope ratio mass spectrometer (Metabolic Solutions, Inc, Nashua, NH), following equilibration with hydrogen gas in the presence of a platinum catalyst. The results of the isotope ratio analysis were reported as a change (delta value) relative to a reference gas. The International Atomic Energy Agency (IAEA) in Vienna, Austria has recommended that all deuterium measurements be expressed relative to the Vienna Standard Mean Ocean Water (V-SMOW). The percentage coefficient of variation was typically $0.75 \%$ daily and varied no more than 2\%. Quality control standards were run throughout the analytical run every day.

A Europa Scientific 20:20 isotope ratio mass spectrometer (Metabolic Solutions, Inc, Nashua, NH) was used for the analysis of

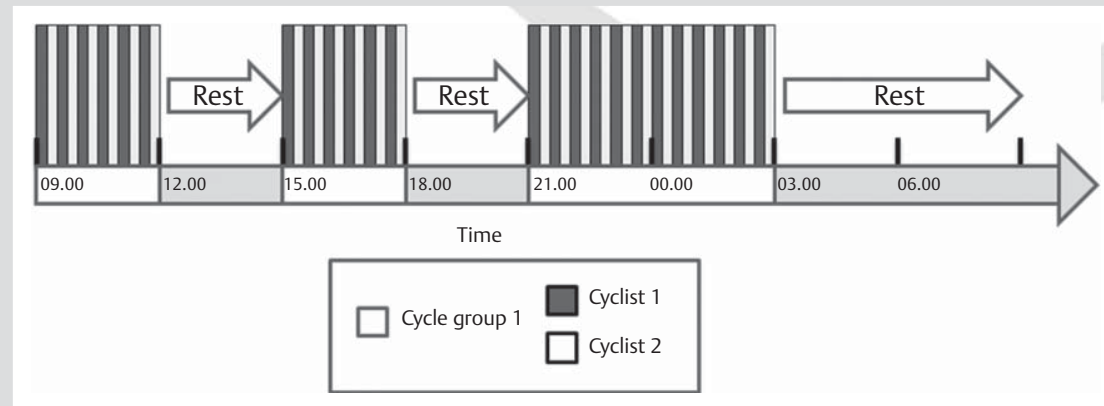

Fig. 1 Schematic of the racing tactic for one cycle group during the RAAM. The other group would cycle during cycle group 1's rest period. 
${ }^{18} \mathrm{O}$ following equilibration with carbon dioxide gas. Known reference materials were analysed in an identical manner before and after batches of samples. The results were reported as delta V-SMOW, similar to the ${ }^{2} \mathrm{H}$ analysis. The percentage coefficient of variation for ${ }^{18} \mathrm{O}$ analysis was typically $0.2 \%$ daily and varied no more than $0.5 \%$.

The delta deuterium and ${ }^{18} \mathrm{O}$ values for the pre-dose $\left(\mathrm{d}_{\text {pre }}\right)$ and post-dose samples $\left(\mathrm{d}_{\text {post }}\right)$ were determined. The doubly labelled dose was diluted with tap water. The amount of dose diluted and water used was recorded. The deuterium and ${ }^{18} \mathrm{O}$ content of the tap water $\left(\mathrm{d}_{\mathrm{tap}}\right)$ and diluted dose $\left(\mathrm{d}_{\text {dose }}\right)$ were measured.

The unprocessed mass spectrometric data was expressed as a fraction of the initial dose given as suggested by the consensus report by the International Dietary Energy Consultancy Group at the 1990 Vienna Austria Meeting [16]. This is achieved using the formula:

$\mathrm{X}=\left(\left(\mathrm{d}_{\text {post }}-\mathrm{d}_{\text {pre }}\right) /\left(\mathrm{d}_{\text {dose }}-\mathrm{d}_{\text {tap }}\right)\right) \mathrm{x}(18.02 \mathrm{a} / \mathrm{WA})$

Where $\mathrm{W}=$ Amount of water (grams) used to dilute the dose, $A=$ Amount of dose (grams) administered to subject, $a=$ amount of dose (grams) diluted for analysis.

Linear regression was used to calculate the slope and intercept of the linear relationship between the time in days and the normalized data for each isotope. The pool sizes $\mathrm{N}_{\mathrm{D}}\left({ }^{2} \mathrm{H}_{2} \mathrm{O}\right)$ and $\mathrm{N}_{\mathrm{O}}$ $\left({ }^{18} \mathrm{O}\right)$ are derived as the reciprocal of the intercept (or plateau value). The intercept of the regression line was the ratio of the pool size spaces $\mathrm{N}_{\mathrm{D}} / \mathrm{N}_{\mathrm{O}}$. The multipoint data were plotted to inspect for any outliers. Any outliers were re-analyzed. The rate constants $\mathrm{k}_{\mathrm{D}}\left({ }^{2} \mathrm{H}_{2} \mathrm{O}\right)$ and $\mathrm{k}_{\mathrm{O}}\left({ }^{18} \mathrm{O}\right)$ were represented by the slope of the regression line. $\mathrm{N}_{\mathrm{D}} / \mathrm{N}_{\mathrm{O}}$ ratios lying outside the range of 1.015 and 1.06 were treated as suspect and samples were reanalyzed.

The mean daily $\mathrm{CO}_{2}$ production $\left(\mathrm{rCO}_{2}\right.$, mol/day) was calculated according to the revised equations [21]:

$\mathrm{rCO}_{2}=(\mathrm{N} / 2.196) \times\left(\mathrm{k}_{0}-1.0427 \mathrm{k}_{\mathrm{D}}\right)$

Where $\mathrm{N}=\left[\left(\mathrm{N}_{\mathrm{O}}\right)+\left(\mathrm{N}_{\mathrm{D}} / 1.0427\right)\right] / 2$

The estimate of energy expenditure was calculated from the carbon dioxide production assuming $127.5 \mathrm{kcal} / \mathrm{mol}$ carbon dioxide (a typical Western diet will produce a respiratory quotient of 0.85 , with $15 \%$ of energy from protein oxidation [16]).

\section{Actigraphy}

Actigraphy is a commonly used technique employed to study sleep-wake patterns by assessing movement, most commonly of the wrist, but also used on the ankle or trunk. It has been stated that actigraphy is based on the principle that during sleep there is a reduced movement [14]. Actigraphy is a relatively accurate instrument for measuring sleep-wake parameters in a number of situations [22] and has been correlated against polysomnography in a number of studies [12]. Studies have shown an accuracy of up to $80 \%$ correlation with polysomnography [3]. For the current study total sleep was measured in minutes every $24-\mathrm{h}$ throughout the entire duration of the RAAM. Total sleep time was an accumulation of all rest periods when the cyclists were able to remain stationary to sleep during the 24 -h period. Measurements were obtained from an Actiwatch and Sleepwatch software (Version 5.28; Cambridge Neurotechnology Ltd, Cambridge, UK) secured to the right ankle of the cyclists. Data was recorded in 1-min epochs (the period of time that the actiwatch data is averaged).

\section{Results}

$\nabla$

\section{Performance}

The cycling team used in this study completed the race in 6 days $10 \mathrm{~h}$ and $51 \mathrm{~min}$ with an average speed of $19.47 \mathrm{mph}(31.33 \mathrm{~km} / \mathrm{h})$. The team finished in third place (out of eleven) in the 4 man team event. The winning team completed the race in 6 days $4 \mathrm{~h}$ and $12 \mathrm{~min}$.

\section{Energy expenditure}

Total mean $( \pm S D)$ EE for each cyclist was $43,401 \pm 3175 \mathrm{kcals}$ with a mean $( \pm$ SD) daily EE $6420 \pm 470$ kcals. O Table 1 gives each cyclist's mean daily EE and total $\mathrm{EE}$ of the entire race.

\section{Energy intake}

During the race the total mean $( \pm S D)$ EI from all food and drink consumed for each cyclist was $29506 \pm 4856$ kcals with a mean $( \pm$ SD) daily El of $4918 \pm 810 \mathrm{kcals}$. The average percentage macronutrient intake was $59 \%$ carbohydrate, $25 \%$ protein and $16 \%$ fat. The percentage of macronutrient intake and mean macronutrient intake measured in grams can be seen along with El for cyclists in $\odot$ Table 2. Mean ( \pm SD) daily fluid intake consisting of sports drinks, water and soft drinks was $5.23 \pm 0.12 \mathrm{~L}$.

\section{Energy deficit}

Results from mean EI and EE resulted in a total mean $( \pm \mathrm{SD})$ energy deficit of $13878 \pm 2672$ kcals with a mean $( \pm$ SD) daily

Tab. 1 Average daily energy expenditure and total energy expenditure.

\begin{tabular}{|lllll}
\hline Cyclist & Mean daily EE & EE/kg BM/day & Total EE & Total EE/kg BM \\
\hline cyclist 1 & 6774 kcals $(28361 \mathrm{~kJ})$ & $81 \mathrm{kcals}(339 \mathrm{~kJ})$ & $45792 \mathrm{kcals}(191722 \mathrm{~kJ})$ & $548 \mathrm{kcals} 2294 \mathrm{~kJ})$ \\
\hline cyclist 2 & $6752 \mathrm{kcals}(28269 \mathrm{~kJ})$ & $75 \mathrm{kcals}(314 \mathrm{~kJ})$ & $45644 \mathrm{kcals}(191102 \mathrm{~kJ})$ & $507 \mathrm{kcals}(2123 \mathrm{~kJ})$ \\
\hline cyclist 3 & $6387 \mathrm{kcals}(26741 \mathrm{~kJ})$ & $82 \mathrm{kcals}(343 \mathrm{~kJ})$ & $43176 \mathrm{kcals}(180769 \mathrm{~kJ})$ & $554 \mathrm{kcals}(2319 \mathrm{~kJ})$ \\
\hline cyclist 4 & $5768 \mathrm{kcals}(24149 \mathrm{~kJ})$ & $79 \mathrm{kcals}(331 \mathrm{~kJ})$ & $38992 \mathrm{kcals}(163525 \mathrm{~kJ})$ & $534 \mathrm{kcals}(2236 \mathrm{~kJ})$ \\
\hline
\end{tabular}

Tab. 2 Daily macronutrient intake (grams and percentage), daily energy intake and total energy intake.

\begin{tabular}{lllllllll} 
Cyclist & \multicolumn{2}{c}{ CHO } & \multicolumn{2}{c}{ Protein } & \multicolumn{2}{c}{ Fat } & Daily El & Total El \\
& grams & $\%$ & grams & $\%$ & grams & $\%$ & & \\
cyclist 1 & $664 \mathrm{~g}$ & $56 \%$ & $182 \mathrm{~g}$ & $17 \%$ & $142 \mathrm{~g}$ & $27 \%$ & $5244 \mathrm{kcals}(21956 \mathrm{~kJ})$ & $31466 \mathrm{kcals}(132742 \mathrm{~kJ})$ \\
\hline cyclist 2 & $788 \mathrm{~g}$ & $59 \%$ & $187 \mathrm{~g}$ & $16 \%$ & $150 \mathrm{~g}$ & $25 \%$ & $5898 \mathrm{kcals}(24694 \mathrm{~kJ})$ & $35386 \mathrm{kcals}(148154 \mathrm{~kJ})$ \\
cyclist 3 & $646 \mathrm{~g}$ & $57 \%$ & $137 \mathrm{~g}$ & $18 \%$ & $92 \mathrm{~g}$ & $25 \%$ & $4412 \mathrm{kcals}(18472 \mathrm{~kJ})$ & $26472 \mathrm{kcals}(110833 \mathrm{~kJ})$ \\
\hline cyclist 4 & $581 \mathrm{~g}$ & $64 \%$ & $126 \mathrm{~g}$ & $14 \%$ & $94 \mathrm{~g}$ & $22 \%$ & $4116 \mathrm{kcals}(17233 \mathrm{~kJ})$ & $24698 \mathrm{kcals}(103406 \mathrm{~kJ})$ \\
\hline
\end{tabular}


Tab. 3 Total and daily energy deficits.

\begin{tabular}{|lll|} 
Cyclist & $\begin{array}{l}\text { Mean daily Energy } \\
\text { Deficit }\end{array}$ & Total Energy Deficit \\
\hline cyclist 1 & 1530 kcals $(6406 \mathrm{~kJ})$ & 14326 kcals $(59980 \mathrm{~kJ})$ \\
\hline cyclist 2 & 854 kcals $(3576 \mathrm{~kJ})$ & 10258 kcals $(42948 \mathrm{~kJ})$ \\
\hline cyclist 3 & $1975 \mathrm{kcals}(8269 \mathrm{~kJ})$ & $16704 \mathrm{kcals}(69936 \mathrm{~kJ})$ \\
\hline cyclist 4 & $1652 \mathrm{kcals}(6917 \mathrm{~kJ})$ & $14224 \mathrm{kcals}(59553 \mathrm{~kJ})$ \\
\hline
\end{tabular}

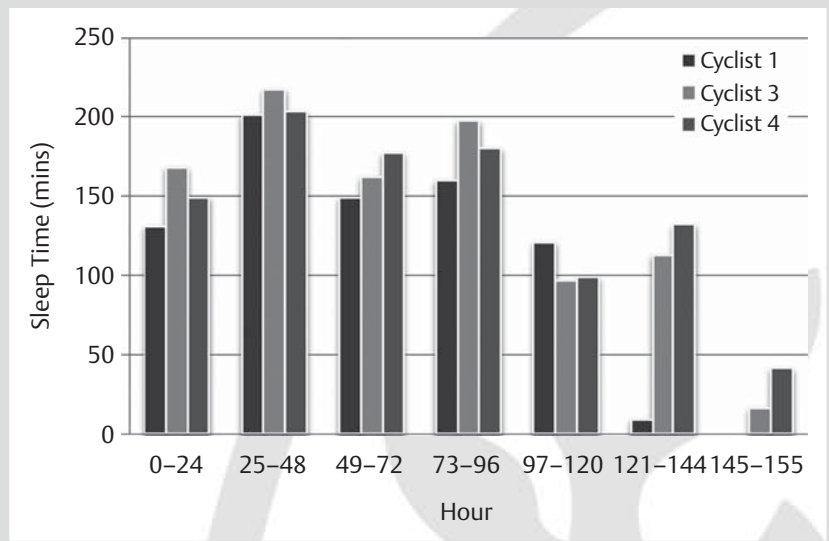

Fig. 2 Actual sleep per race day for each of the three cyclists.

energy deficit of $1503 \pm 471$ kcals. Table 3 highlights the total and daily energy deficit for each cyclist.

Total sleep

Actigraphy data was only available in three riders due to a malfunction in cyclist two's device. The total mean $( \pm S D)$ sleep time was only $129.6 \pm 16.9 \mathrm{~min}$ per race day for the three cyclists measured throughout the RAAM. 0 Fig. 2 illustrates a large intra-variation between the cyclists and a gradual decrease in sleep time towards the end of the race.

\section{Discussion}

$\nabla$

The aim of this study was to investigate the EE using the gold standard method during the team event at the RAAM 2008. The findings of the current study were that the mean $( \pm S D)$ EE for each individual of a 4-man team was $43401 \pm 3175 \mathrm{kcals}$, with a mean $( \pm$ SD) daily EE of $6420 \pm 470$ kcals. The team completed the race in third place in a time of 6 days $10 \mathrm{~h}$ and $51 \mathrm{~min}$.

\section{Energy expenditure}

In comparison with the current study, a previous study measured EE during the RAAM with a solo rider and found that the subject expended a total energy of $179650 \mathrm{kcal}$, with a mean ( \pm SD) of $17965+2165 \mathrm{kcal}$ per day, during the 9 days $16 \mathrm{~h}$ and 45 min [11]. However, the method used to measure EE was calculated based on heart rate measurement. This method has been shown to produce errors of up to $30 \%$ during $24 \mathrm{~h}$ assessment in individuals, as HR does not increase as steeply for given changes in EE at lower levels of EE, possibly due to postural changes in stroke volume [1]. Other limitations of HR monitoring for EE include psychological stress, hydration levels and environmental factors such as temperature and humidity, all of which are affected during the RAAM. It has been suggested that the HR method is best used to provide information on activity patterns and levels of exercise intensity, and to be used in addition to DLW as HR measurements show large variation around the mean agreement with DLW method [7].

A previous study measured EE using DLW with 4 professional cyclists competing in the Tour de France and found that the mean daily EE over a three week period was 8054 kcals (1560$1750 \mathrm{~kJ} / \mathrm{day}^{-1} / \mathrm{kg}^{-0.72}$ ) [25]. This equates to $4.3-5.2$ times the basal metabolic rate (BMR). Another study also investigated EE during the Tour de France and recorded a mean EE of 6066 kcals/ day with four professional cyclists [17], calculated using previous equations [27,9] based on cycle speed, time, altitude and factors for air resistance, rolling resistance and weight.

\section{Energy intake}

The average EI for the duration of the RAAM was 29506 kcals, with an average daily EI of $4918 \mathrm{kcals}$, which is similar to that reported with endurance runners during a 20 day $500 \mathrm{~km}$ road race who consumed $4824 \mathrm{kcals}$ per day [8]. However two previous studies have examined the EI of solo finishers from the RAAM $[6,13]$ and reported EI of 7950 and 8429 kcals, respectively. From the current study the EI did not match that of the EE and resulted in an average energy deficit of 15361 kcals for the entire race. This is in contrast to a previous study [17] that reported a well matched EI (6138 kcal) and EE (6066 kcal) with 5 professional cyclists competing in the Tour de France. However, the Tour de France is a multi stage event with more time available for the cyclists to refuel before and after each stage during the event. A possible suggestion for the low EI during this study could be related to the non-stop nature of the event. The cyclists struggled to consume larger more substantial meals during their rest periods, tending to rather constantly graze throughout the race which resulted in the cyclist struggling with the constant intake of sweet carbohydrate sports drinks, gels and bars. Even though the cyclists in the current study consumed the recommended macronutrient intake of between $6-10 \mathrm{~g} / \mathrm{kg}$ body weight of carbohydrate [2] and approximately $1.6 \mathrm{~g} / \mathrm{kg}$ body weight of protein [24] for ultra endurance exercise, the overall EI was significantly less than the overall EE. The cyclists in the present study failed to emulate the energy intake of another RAAM study [13] in which their solo rider successfully completed the RAAM consuming 8429 kcals per day and a study in which a $24 \mathrm{~h}$ cycle event cyclist consumed $10576 \mathrm{kcal}$ [26]. Albeit the cyclists in the present study consumed less than the cyclists used by others $[11,26]$, the percentage of EI to EE was more in the present study. The EI during the present study was $68 \%$ of the EE, which was greater than previous studies $[11,26]$ who reported an EI of $53 \%$ and $54 \%$ of the EE, respectively.

Sleep

This study demonstrates that continuous ultra endurance events such as the RAAM, also act as sleep deprivation challenges. Riding in the 4-man team event was associated with significant disruption to the quantity of sleep, an example of which can be seen with one cyclist getting only 9 min sleep in over $24 \mathrm{~h}$. The lack of sleep found with the cyclists in this study emphasizes a poor recovery between exercise bouts. Due to the wide variation between the cyclists in the amount of sleep disruption experienced, interventions to improve sleep quantity and quality during multi-day ultra-endurance events such as the RAAM should be individually based. It has been suggested that sleep may be related to recovery from fatigue and to assist in the build up of energy [15]. Furthermore, during sleep there is a reduction in 
the metabolic requirements within the body [4]. The sleep deprivation accompanied with the energy deficit highlights the difficulty in completing such events as recovery is compromised throughout.

\section{Limitation of the present study}

Some limitations of the current technique are noteworthy, specifically DLW is unable to provide information about peak energy expenditure periods over short bouts of exercise throughout the race and this is a disadvantage of this method. The failure to measure body weight post race to identify any weight losses due to an imbalance in EI and EE was also a limitation. However, previous research $[5,11,23]$ all successfully measured weight loss following ultra endurance exercise. One study [11] demonstrated a total body mass loss of $5 \mathrm{~kg}$ in a solo rider competing in the RAAM. This body mass loss resulted from a total energy deficit of $83526 \mathrm{kcal}$ and is significantly greater than the energy deficit found in the cyclists in the current study (11878-18237 kcal), albeit the present study participants completed the RAAM in a four man team.

There were no gastrointestinal complaints during the RAAM, but cyclists did suffer from feelings of fullness, likely exacerbated by the sleep deprivation observed in this study. Due to the continuous nature of the event, the cyclists did find it difficult to consume the same carbohydrate electrolyte drinks throughout and also found it arduous to keep consuming high numbers of energy gels and bars. Therefore the task for future coaches and nutritionists is to design diets that vary in taste, while maintaining a high energy intake. A difficulty putting this into practise during ultra endurance events like the RAAM is the fact that a lot of food and drink has to be bought on the road during the race and that cooking facilities are limited.

\section{Conclusion}

\section{$\nabla$}

The high EE, three times that of a typical EI for males, highlights the need for correct and practical dietary strategies and challenges nutritionists to devise high energy diets that not only contain the correct macronutrient balance, but are also palatable to the cyclists, thus encouraging a higher EI. The findings from this study will be of benefit to cyclists, coaches and nutritionists participating in the RAAM and other ultra endurance events in the future.

\footnotetext{
Affiliations

${ }^{1}$ Liverpool John Moores University, Research Institute of Sport \& Exercise Sciences, Liverpool, United Kingdom

${ }^{2}$ University of Wolverhampton, School of Sports, Performing Arts and Leisure, Walsall, United Kingdom

${ }^{3}$ Brunel University, Department of Sport and Exercise Science, Uxbridge, United Kingdom

${ }^{4}$ University of British Colombia, Sport Science Department, Vancouver, Canada

${ }^{5}$ Aspetar, Qatar Orthopedic and Sports Medicine Hospital, Doha, Qatar ${ }^{6}$ St Mary's University College, School of Human Sciences, Twickenham, United Kingdom
}

\section{References}

1 Ainslie PN, Reilly T, Westerterp KR. Estimating human energy expenditure, a review of techniques with particular reference to doubly labelled water. Sports Med 2003; 33: 683-698

2 Applegate EA. Nutritional considerations for ultraendurance performance. Int J Sport Nutr 1991; 1: 118-126

3 Babin L, Lee S, Halko S, Boudreau AC, George CFP. Determining sleepwake activity using actiwatch. Sleep Res 1997; 26: 640

4 Berger RJ, Phillips NH. Comparative aspects of energy metabolism, body temperature and sleep. Acta Physiol Scand Suppl 1988; 133: 21-28

5 Bircher S, Enggist A, Jehle T, Knechtle B. Effects of an extreme endurance race on energy balance and body composition - a case study. J Sports Sci Med 2006; 5: 154-162

6 Clark N, Tobin J Jr, Ellis C. Feeding the ultraendurance athlete: practical tips and a case study. J Am Diet Assoc 1992; 92: 1258-1262

7 Davidson L, McNeill G, Haggarty P, Smith JS, Franklin MF. Free-living energy expenditure of adult men assessed by continuous heart-rate monitoring and doubly-labelled water. Br J Nutr 1997; 78: 695-708

8 Dressendorfer RH, Wade CE, Hornick C, Timmis GC. High-density lipoprotein-cholesterol in marathon runners during a 20-day road race. JAMA 1982; 247: 1715-1717

9 Faria IE, Cavanagh PR. The Physiology and Biomechanics of Cycling. New York, J.Whiley; 1978

10 Harriss DJ, Atkinson G. International Journal of Sports Medicine - Ethical Standards in Sport and Exercise Science Research. Int J Sports Med 2009; 30: 701-702

11 Knechtle B, Enggist A, Jehle T. Energy turnover at the Race Across AMerica (RAAM) - a case report. Int J Sports Med 2005; 26: 499-503

12 Kushida CA, Chang A, Gadkary C, Guilleminault C, Carrillo O, Dement WC. Comparison of actigraphic, polysomnographic, and subjective assessment of sleep parameters in sleep-disordered patients. Sleep Med 2001; 2: 389-396

13 Lindeman AK. Nutrient intake of an ultraendurance cyclist. Int J Sport Nutr 1991; 1: 79-85

14 Littner M, Kushida CA, Anderson WM, Bailey D, Berry RB, Davila DG, Hirshkowitz M, Kapen S, Kramer M, Loube D, Wise M, Johnson SF. Practice parameters for the role of actigraphy in the study of sleep and circadian rhythms: an update for 2002. Sleep 2003; 26: 337-341

15 Oswald I. Sleep as a restorative process: human clues. Prog Brain Res 1980; 53: 279-288

16 Prentice AM (ed.). The doubly-labeled water method for measuring energy expenditure: technical recommendations for use in humans. Vienna: NAHRES-4, International Atomic Energy Agency; 1990

17 Saris WHM, van Erp-Baart MA, Brouns F, Westerterp KR, ten Hoor F. Study on food intake and energy expenditure during extreme sustained exercise: The Tour de France. Int J Sports Med 1989; 10 : S26-S31

18 Schoeller DA. Measurement of energy expenditure in free-living humans by using doubly labeled water. J Nutr 1988; 118: 1278-1289

19 Schoeller DA. Validation of habitual energy intake. Public Health Nutr 2002; 5: 883-888

20 Singh A, Pelletier PA, Deuster PA. Dietary requirements for ultra-endurance exercise. Sports Med 1994; 18: 301-308

21 Speakman JR, Sreekumarun NK, Goran MI. Revised equations for calculating $\mathrm{CO}_{2}$ production from doubly labeled water in humans. Am J Physiol 1993; 264: E912-917

22 Stanley $N$. Actigraphy in human psychopharmacology: a review. Hum Psychopharmacol 2003; 18: 39-49

23 Stewart IB, Steward KL. Energy balance during two days of continuous stationary cycling. J Int Soc Sports Nutr 2007; 4: 15-21

24 Tarnopolsky MA, MacDougall JD, Atkinson A. Influence of protein intake and training status on nitrogen balance and lean body mass. J Appl Physiol 1988; 64: 187-193

25 Westerterp KR, Saris WHM, van Es M, ten Hoor F. Use of the doubly labeled water technique in humans during heavy sustained exercise. J Appl Physiol 1986; 61: 2162-2167

26 White JA, Ward C, Nelson H. Ergogenic demands of a $24 \mathrm{~h}$ cycling event. Br J Sports Med 1984; 18: 165-171

27 Whit FR, Wilson DG. Bicycling Science. Cambridge, MIT Press; 1974 